\title{
Novos Processos de Reciclagem de Chumbo
}

\author{
Chacón-Sanhueza, A. E ${ }^{\mathrm{a}}$; Fontanetti, A. R ${ }^{\mathrm{b}}$ \\ a - POSMAT - Faculdade de Ciências - UNESP - Bauru - SP - Brasil. \\ e-mail: abelchacon@yahoo.com.br \\ b - Indústrias Tudor SP. de Baterias Ltda.- Rua José Pinelli, 2-130 - CEP - 17039-741, Bauru - SP - Brasil \\ e-mail: arfont@ig.com.br
}

\section{RESUMO}

O processo pirometalúrgico convencional para a produção de chumbo metálico é comparado com dois novos processos ambientalmente não agressivos: o eletrohidrometalúrgico e fusão alcalina.

O processo eletrohidrometalúrgico consiste em reduzir o tamanho das partículas dos compostos de chumbo e lixiviar os mesmos com uma solução ácida de fluoborato férrico. Neste ponto, o chumbo é dissolvido com os íons férricos sendo reduzidos a íons ferrosos. A solução resultante da lixiviação é bombeada para os compartimentos catódicos de uma célula eletrolítica de diafragma nos quais o chumbo metálico é depositado em catodos de aço inoxidável numa forma compacta e pura. A solução que é empobrecida em íons $\mathrm{Pb}^{2+}$ é então enviada aos compartimentos anódicos da mesma célula onde, nas superfícies de anodos ocorre a oxidação dos íons ferrosos a férricos, que retornam ao estágio de lixiviação.

$\mathrm{O}$ processo de fusão alcalina consiste em se juntar soda cáustica fundida, enxofre e compostos de chumbo num reator a uma temperatura entre $600{ }^{\circ} \mathrm{C} \mathrm{e} 700{ }^{\circ} \mathrm{C}$. Como um resultado chumbo metálico é obtido juntamente com sais fundidos de sódio, sulfetos metálicos e borra. O fundido é processado, resultando em borra, sulfetos metálicos, soda cáustica e enxofre. Estes dois últimos retornam para o reator.

Ambos os processos permitem a recuperação de metais como antimônio, estanho, enxofre e prata, que em processo convencional são perdidos na escória.

Esses novos processos são ambientalmente corretos sem poluições severas de $\mathrm{Pb}_{\text {e }} \mathrm{SO}_{2}$. O chumbo metálico obtido é mais puro que aquele do processo convencional.

Palavras chaves: Chumbo, processo eletrohidrometalúrgico, fusão alcalina e meio ambiente.

\section{New Lead Recycling Processes}

\section{ABSTRACT}

The conventional pirometallurgical process for the production of metallic lead is compared with two innovative clean processes: electrohydrometallurgical and alkaline smelting.

The electrohydrometallurgical process consists on reducing the particle size of the lead compounds and leaching them with an acidic solution of ferric fluoroborate. In this step, lead is dissolved with the ferric being reduced to ferrous ions. The resulting solution from the leaching step is sent to the cathodic compartment of a diaphragm cell in which lead is deposited on a cathode of stainless steel, in compact and pure form. The solution that is depleted of lead ions is then sent to the anodic compartment of the same cell where a suitable anode oxidizes ferrous to ferric ions that turn back to the leaching step.

The alkaline smelting process consists in feeding molten caustic soda, sulfur and lead compounds into a reaction reactor at temperature of $600-700^{\circ} \mathrm{C}$. As a result metallic lead is obtained together with a melt containing sodium salts, metal sulfides and gangue. The melt is processed yielding gangue, metal sulfides, caustic soda and sulfur. These two last turn back to the reaction reactor.

Both processes allow the recovery of valuable metals such as antimony, tin, sulfur and silver that in conventional process are losing in the slag.

These innovate processes are ecologically cleaning processes without serious pollution of $\mathrm{Pb}$ and $\mathrm{SO}_{2}$. The obtained metallic lead is purer than that from conventional process and seldom contains any impurity.

Keywords: Lead, electrohydrometallurgical process, alkaline smelting process and environment. 


\section{INTRODUÇÃO}

Os atuais sistemas de produção de chumbo não atendem adequadamente as exigências dos organismos de controle ambiental e os anseios da sociedade em geral. Por isso, somente no Brasil, foram fechadas empresas que em conjunto produziam 60.000 toneladas deste metal por ano e eram fontes diretas de emprego para 600 famílias [1].

Os métodos de recuperação de chumbo convencionais utilizam processos pirometalúrgicos em fornos tipos cuba, revérberos, rotativos ou outros tipos de fornos elétricos que liberam gases $\mathrm{SO}_{\mathrm{x}} \mathrm{e}$ particulados de chumbo para a atmosfera, além de gerar borra metálica que atinge níveis de $25 \%$ da quantidade de chumbo produzida [2]. Embora esta borra contenha chumbo, antimônio, arsênio, estanho, prata e outros metais, têm sido realizados grandes esforços para classificar este material como resíduo não lixiviável. Entretanto este ainda continua sendo considerado resíduo altamente perigoso e deve ser disposto em aterro industrial classe 01 , aumentando consideravelmente os custos.

Uma das alternativas inovadoras para recuperar o chumbo da pasta ativa oriunda de baterias chumbo-ácido exauridas e outros resíduos é promover uma fusão alcalina utilizando as mesmas instalações existentes nos processos convencionais (processo pirometalúrgico). Pelo processo de fusão alcalina, quantidades otimizadas de matéria-prima rica em compostos de chumbo, soda cáustica e enxofre são colocados em um reator químico (fornos estacionários) e levados a $600-700^{\circ} \mathrm{C}$ (ver Figura 1).

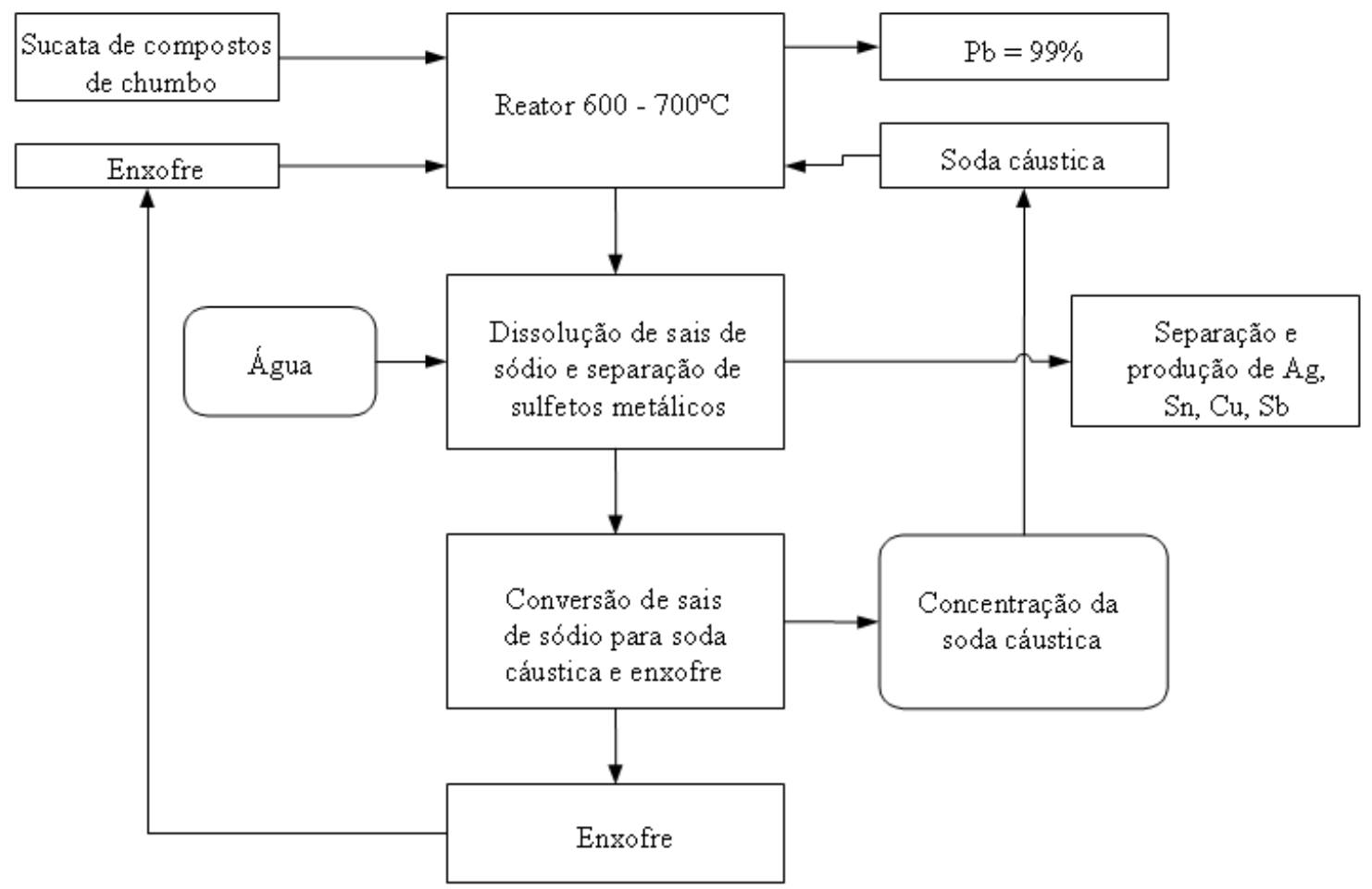

Figura 1: Diagrama de produção de chumbo por fusão alcalina.

Neste processo o enxofre reage com a soda cáustica formando sulfeto de sódio e tiossulfato de sódio, que reagem separadamente com os compostos de chumbo formando sulfeto deste metal, conforme as seguintes equações químicas [4]].

$$
\begin{aligned}
& 4 \mathrm{~S}+6 \mathrm{NaOH} \rightarrow 2 \mathrm{Na}_{2} \mathrm{~S}+\mathrm{Na}_{2} \mathrm{~S}_{2} \mathrm{O}_{3}+3 \mathrm{H}_{2} \mathrm{O} \\
& \mathrm{PbO}+\mathrm{Na}_{2} \mathrm{~S}_{2} \mathrm{O}_{3} \rightarrow \mathrm{PbS}+\mathrm{Na}_{2} \mathrm{SO}_{4}
\end{aligned}
$$




$$
\begin{aligned}
& 4 \mathrm{PbO}_{2}+5 \mathrm{Na}_{2} \mathrm{~S}_{2} \mathrm{O}_{3}+\mathrm{H}_{2} \mathrm{O} \rightarrow 4 \mathrm{PbS}+5 \mathrm{Na}_{2} \mathrm{SO}_{4}+\mathrm{H}_{2} \mathrm{SO}_{4} \\
& \mathrm{PbSO}_{4}+\mathrm{Na}_{2} \mathrm{~S}_{2} \mathrm{O}_{3}+\mathrm{H}_{2} \mathrm{O} \rightarrow \mathrm{PbS}+\mathrm{Na}_{2} \mathrm{SO}_{4}+\mathrm{H}_{2} \mathrm{SO}_{4} \\
& \mathrm{PbO}+\mathrm{Na}_{2} \mathrm{~S}+\mathrm{H}_{2} \mathrm{SO}_{4} \rightarrow \mathrm{PbS}+\mathrm{Na}_{2} \mathrm{SO}_{4}+\mathrm{H}_{2} \mathrm{O} \\
& \mathrm{PbO}_{2}+2 \mathrm{Na}_{2} \mathrm{~S}+2 \mathrm{H}_{2} \mathrm{SO}_{4} \rightarrow \mathrm{PbS}+2 \mathrm{Na}_{2} \mathrm{SO}_{4}+2 \mathrm{~S}^{0}+2 \mathrm{H}_{2} \mathrm{O} \\
& \mathrm{PbSO}_{4}+\mathrm{Na}_{2} \mathrm{~S} \rightarrow \mathrm{PbS}+\mathrm{Na}_{2} \mathrm{SO}_{4}
\end{aligned}
$$

Algumas destas reações que acontecem no reator são utilizadas a temperatura ambiente para a transformação do sulfato de chumbo (sal de alto ponto de fusão e de difícil redução química), em compostos de chumbo que têm maior facilidade de utilização nos processos convencionais de reciclagem de baterias chumbo-ácido e também nas tentativas de implementação de processos eletroquímicos []].

O sulfeto de chumbo formado reage com o hidróxido de sódio de acordo com a seguinte equação de óxido-redução:

$$
4 \mathrm{PbS}+8 \mathrm{NaOH} \rightarrow 4 \mathrm{~Pb}^{0}+3 \mathrm{Na}_{2} \mathrm{~S}+\mathrm{Na}_{2} \mathrm{SO}_{4}+4 \mathrm{H}_{2} \mathrm{O}
$$

Após a separação do chumbo metálico, os sais sódicos podem ser transformados em soda cáustica e enxofre de acordo às técnicas já existentes []] e que serão mais discutidos quando se abordar os aspectos cinéticos do processo. Tanto a soda cáustica como o enxofre retornam ao processo, assegurando a viabilidade econômica deste desenvolvimento.

\section{REVERSÃO DE SAIS SÓDICOS PARA SODA E ENXOFRE}

Importantes processos produtivos apresentam entre seus resíduos, o sulfato de sódio e outros sais sódicos. Esses compostos são lançados juntamente com os efluentes líquidos, sendo permitido o despejo deste material em grandes fluxos de água, por exemplo, rios. Entretanto em lugares densamente habitados a concentração permitida para estes sais é de no máximo 1000 ppm. A tendência atual é de se limitar a todos os efluentes tais níveis de concentração.

Como se pode verificar por meio das equações (de 1 a 8 ), o processo aqui proposto, gera como resíduos sais sódicos (como sulfato e sulfeto). Deste modo uma forma de viabilizar economicamente o mesmo, é a recuperação de soda cáustica e enxofre a partir dos sais citados. Além disso, seria uma importante tecnologia a ser aplicada para minimizar o impacto ambiental de processos geradores do mesmo tipo de resíduos.

A primeira etapa deste procedimento consiste na conversão dos sais sódicos em sulfeto de sódio de acordo as seguintes reações químicas:

$$
\begin{aligned}
& \mathrm{Na}_{2} \mathrm{SO}_{4}+\mathrm{BaS} \rightarrow \mathrm{BaSO}_{4}+\mathrm{Na}_{2} \mathrm{~S} \\
& \mathrm{Na}_{2} \mathrm{SO}_{3}+\mathrm{BaS} \rightarrow \mathrm{Ba} \mathrm{SO}_{3}+\mathrm{Na}_{2} \mathrm{~S} \\
& \mathrm{NaHSO}_{3}+\mathrm{BaS}+\mathrm{NaOH} \rightarrow \mathrm{Ba} \mathrm{SO}_{3}+\mathrm{Na}_{2} \mathrm{~S}
\end{aligned}
$$

Os sulfatos e sulfitos de bário insolúveis são separados por filtração e reduzidos termicamente com carvão de acordo as reações:

$$
\mathrm{BaSO}_{4}+2 \mathrm{C} \rightarrow \mathrm{BaS}+2 \mathrm{CO}_{2}
$$




$$
\mathrm{Ba} \mathrm{SO}_{3}+3 \mathrm{C} \rightarrow \mathrm{BaS}+3 \mathrm{CO}
$$

A solução de sulfeto de sódio obtida das filtrações dos produtos das reações 9,10 e 11 é diluída a concentrações em torno de $100 \mathrm{~g} / \mathrm{L}$, ficando pronta para envio à célula eletrolítica de diafragma (ver Figura 2).

Essa solução vai para o compartimento anódico (2) da célula eletrolítica (1), sendo que neste compartimento ocorre a oxidação do sulfeto, de acordo com a seguinte equação química:

$$
\mathrm{Na}_{2} \mathrm{~S} \rightarrow 2 \mathrm{Na}^{+}+\mathrm{S}^{0}+2 \mathrm{e}^{-}
$$
química:

O compartimento catódico (3) é alimentado com água que se reduz, de acordo a seguinte equação

$$
2 \mathrm{H}_{2} \mathrm{O}+2 \mathrm{e}^{-} \rightarrow 2 \mathrm{OH}^{-}+\mathrm{H}_{2}(\mathrm{~g})
$$

Os cátions $\mathrm{Na}^{+}$, migra através da membrana catiônica (4) formando soda cáustica, que é retirada continuamente da célula e enviada ao tanque de solução de soda (7), a solução do compartimento anódico (anolito) é retirada continuamente e filtrada (5), obtendo-se a solução (8) que retorna ao processo eletroquímico e o enxofre que é armazenado (6).

Somando-se as equações (14) e (15) obtém-se:

$$
\mathrm{Na}_{2} \mathrm{~S}+2 \mathrm{H}_{2} \mathrm{O} \rightarrow 2 \mathrm{NaOH}+\mathrm{S}^{0}+\mathrm{H}_{2}(\mathrm{~g})
$$

Quanto aos aspectos cinéticos do processo, pode-se afirmar que o mérito do mesmo é predizer que as reações de conversão de sulfato de chumbo em óxidos e/ou sulfetos de sódio em meio aquoso a temperatura ambiente, bem como as reações dos óxidos de chumbo (reações 2 a 7) [4], são muito rápidas no estado fundido [6]. Há que se enfatizar também o fato interessante de que a reação (1) que dá origem ao processo é também da mesma ordem de velocidade no estado fundido []. Isso permite que todo o processo de reações paralelas possa dar origem, num único conjunto de procedimentos, à reação principal de produção de chumbo, ou seja, a reação (8).

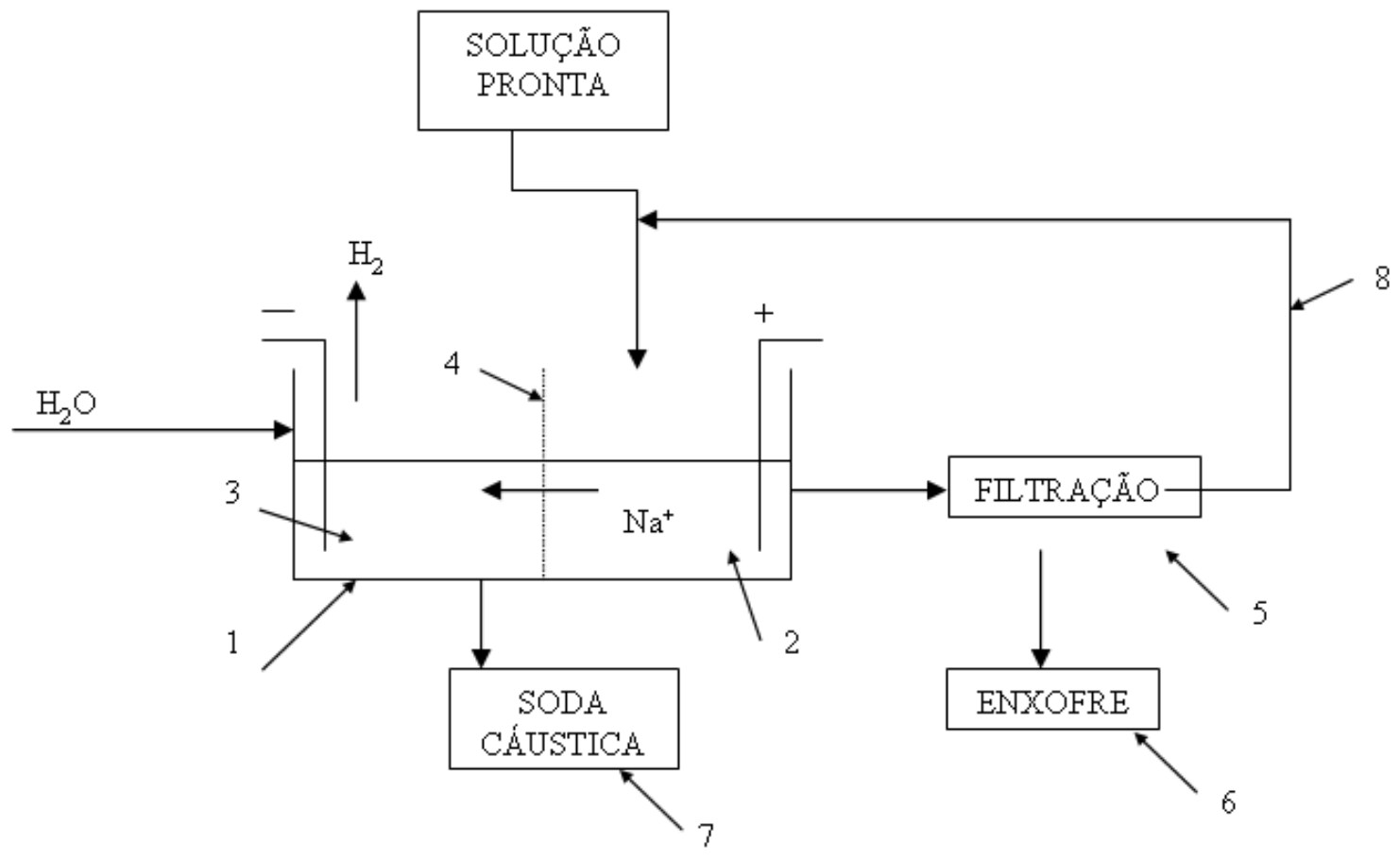

Figura 2: Diagrama da reversão de sulfeto de sódio para soda cáustica e enxofre. 
Dado a importância destes processos cinéticos químicos buscam-se recursos para se estudar os mecanismos destas reações e se tentar avaliar as suas ordens de reação, assim como as energias de ativação individuais, além da energia de ativação do processo global. Conforme apresentado anteriormente, nos eletrodos da célula de diafragma ocorre [5] :

$$
\begin{array}{ll}
\text { No anodo: } & \mathrm{Na}_{2} \mathrm{~S} \rightarrow 2 \mathrm{Na}^{+}+\mathrm{S}^{0}+2 \mathrm{e}^{-} \\
\text {No catodo: } & 2 \mathrm{H}_{2} \mathrm{O}+2 \mathrm{e}^{-} \rightarrow 2 \mathrm{OH}^{-}+\mathrm{H}_{2}(\mathrm{~g})
\end{array}
$$

Somando-se as duas últimas reações obtém-se:

$$
\mathrm{Na}_{2} \mathrm{~S}+2 \mathrm{H}_{2} \mathrm{O} \rightarrow 2 \mathrm{NaOH}+\mathrm{S}^{0}+\mathrm{H}_{2}(\mathrm{~g})
$$

Um aperfeiçoamento do processo de reversão de sais de sódio, é a adição ao anolito de $5 \mathrm{~g} / 1 \mathrm{de}$ iodeto de sódio $(\mathrm{NaI})$, que tem um potencial de oxidação intermediário aos potenciais das reações 14 e 15 , atuando como catalisador.

A representação eletroquímica da ação catalítica do iodeto de sódio é a seguinte:

No anodo: $\quad 2 \mathrm{NaI} \rightarrow 2 \mathrm{Na}^{+}+\mathrm{I}_{2}+2 \mathrm{e}^{-}$

Na solução: $\quad \mathrm{I}_{2}+\mathrm{Na}_{2} \mathrm{~S} \rightarrow 2 \mathrm{NaI}+\mathrm{S}^{0}$

Reação total: $\quad \mathrm{Na}_{2} \mathrm{~S} \rightarrow 2 \mathrm{Na}^{+}+\mathrm{S}^{0}+2 \mathrm{e}^{-}$

Esse procedimento adicional traz os seguintes benefícios:

- Redução do potencial da célula, pela diminuição de voltagem de polarização, com a conseqüente diminuição do consumo de energia elétrica;

- Aumento da cinética de reação de oxidação, diminuindo o limiar de concentração de sulfeto de sódio no processo.

- Como as reações acontecem mais rapidamente, se pode operar a densidade de corrente mais alta, diminuindo os tamanhos da célula e dos eletrodos, o que diminui consideravelmente os custos de investimento.

Uma alternativa inovadora para produzir chumbo é preparar e submeter a matéria prima com compostos de chumbo à lixiviação com fluoborato férrico[7, 8], para solubilizar os íons chumbo e reduzir os íons férricos para íons ferrosos. Os íons $\mathrm{Pb}^{2+}$ são eletrodepositados, com pureza superior a 99,99\%, sobre um substrato de aço inox. No compartimento anódico da célula de diafragma os íons $\mathrm{Fe}^{2+}$, são oxidados a $\mathrm{Fe}^{3+} \mathrm{e}$ estes são enviados ao reator lixiviador dando seqüência ao ciclo, como se pode verificar na Figura 3.

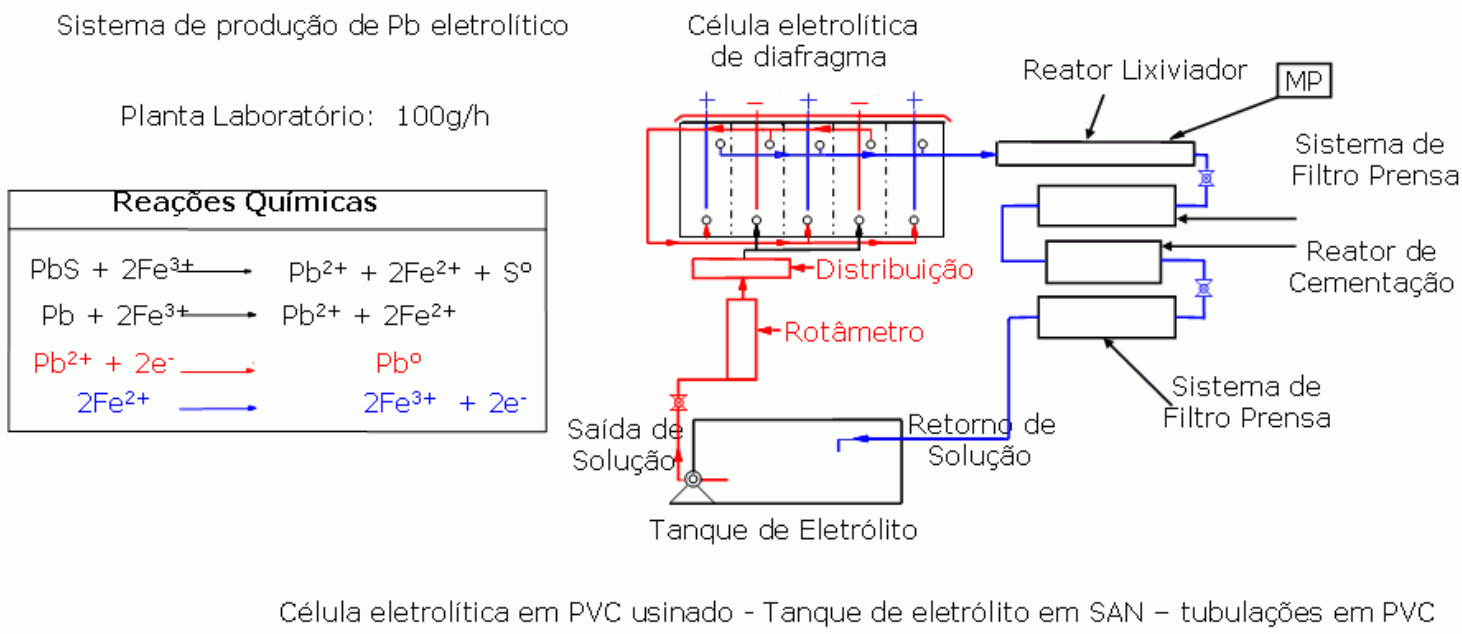

Figura 3: Diagrama esquemático do processo eletrohidrometalúrgico de produção de chumbo 
Este processo esta sendo aperfeiçoado na microempresa Global Eletroquímica (Bauru-SP-Brasil) para funcionar continuamente por períodos de tempo de 800 a 1000 horas. Com isto, espera-se otimizar as variáveis operacionais e registrar brevemente patente deste inovador processo alternativo de produção de chumbo.

\section{MATERIAIS E MÉTODOS}

Para avaliar o processo pirometalúrgico foi utilizado o banco de dados da unidade de reciclagem de Governador Valadares, MG, Brasil, da empresa Indústrias Tudor-SP de Baterias Ltda.

A avaliação do processo eletrohidrometalúrgico foi efetuada numa mini planta, que está esquematicamente representada no diagrama de fluxo da Figura 3, onde as linhas correspondem à circulação do anolito e do catolito. No catodo de aço inox se deposita chumbo e no anodo se oxida a solução de fluoborato de ferro II, que depois passa para o reator lixiviador onde dissolve os compostos de chumbo. As impurezas metálicas são decantadas quimicamente e filtradas antes de retornar ao tanque alimentador de solução. Este sistema de trabalho pode ser observado na Figura 4.

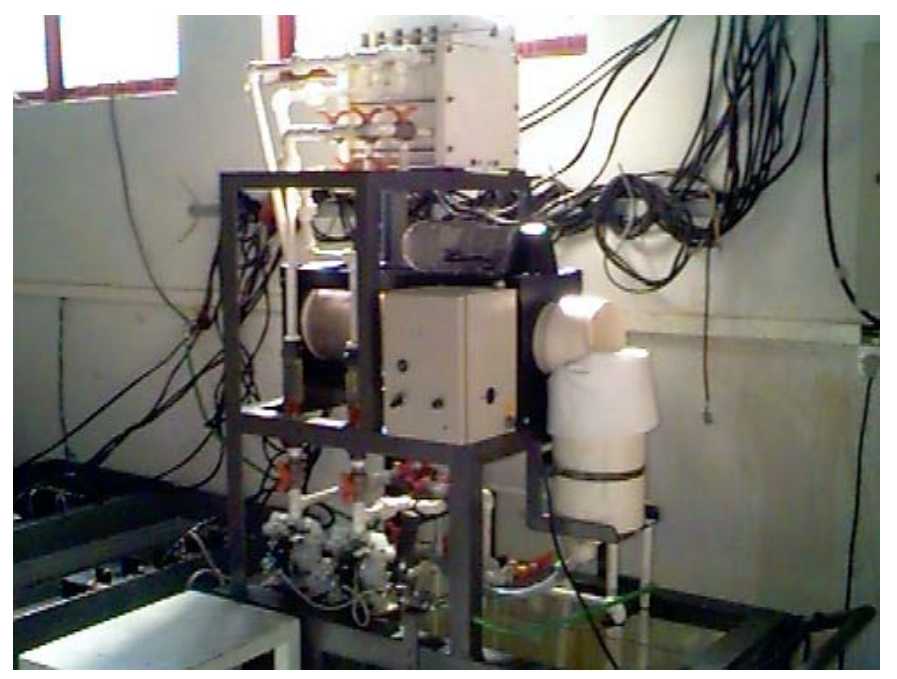

Figura 4: Sistema eletrohidrometalúrgico de produção de chumbo.

O sistema de produção por técnicas de fusão alcalina, observado na Figura 5, foi ensaiado no laboratório da mesma empresa por meio do estudo de cada una das suas atividades, que podem ser deduzidas da Figura 1. 


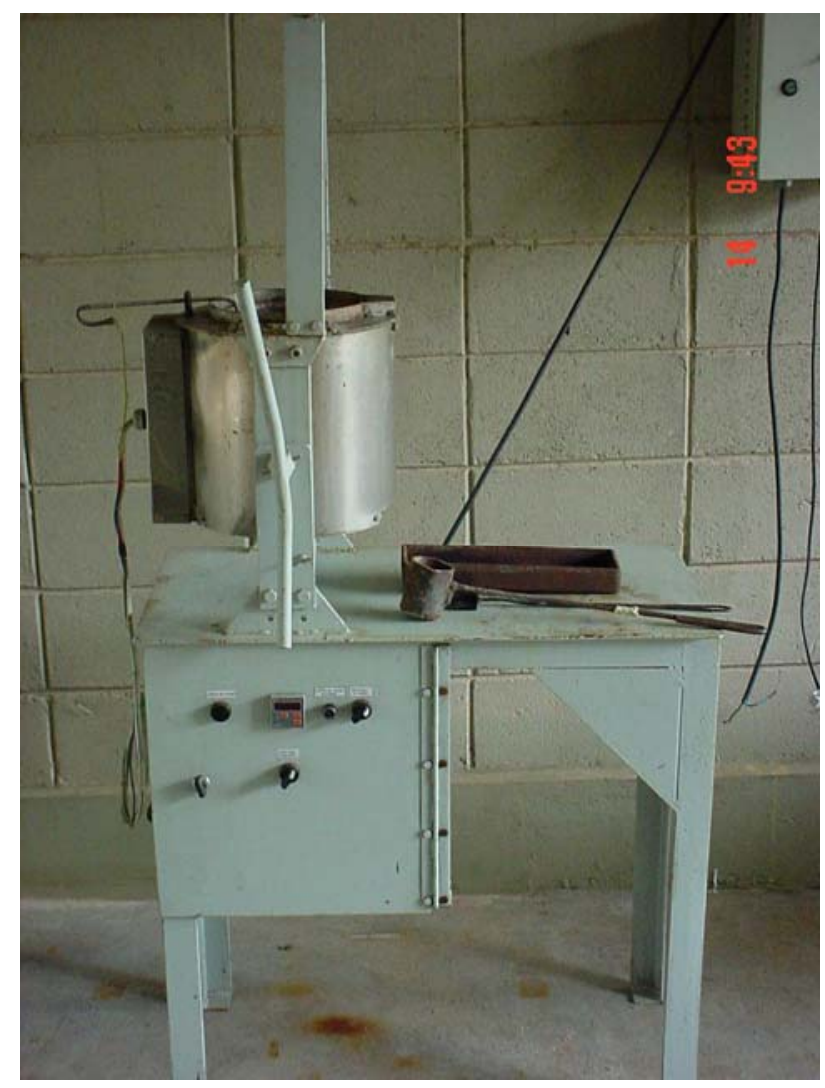

Figura 5: Sistema de Fusão Alcalina para produção de chumbo.

Por meio destes sistemas também é possível recuperar outros metais (antimônio, arsênio, prata e estanho) que nos sistemas convencionais de produção em uso se perdem nas escorias que são depositadas em caríssimos sistemas especiais para substâncias contaminadas. A recuperação dos sulfetos daqueles metais e outros elementos químicos pode ser efetuada por técnicas de extração por solventes orgânicos. Isto continua pendente e estudos serão realizados em atividades adicionais.

\section{RESULTADOS, DISCUSSÕES E CONCLUSÕES.}

Na Tabela 1 se pode observar a pureza média do chumbo obtido nos três processos discutidos neste trabalho. O chumbo obtido pelo processo eletrohidrometalúrgico atende as necessidades das mais modernas baterias. O produto do processo de fusão alcalina necessita de uma leve operação de purificação e o metal do processo pirometalúrgico necessita profundamente de refino químico.

Tabela 1: Composição química porcentual, determinada pela técnica de emissão ótica, do chumbo obtido nos três processos discutidos.

\begin{tabular}{|l|c|c|c|c|c|c|c|c|c|}
\hline \multicolumn{1}{|c|}{ Processo } & Sb & As & Bi & Cu & Sn & Ag & Zn & Se & Pb \\
\hline Eletrohidrometalúrgico & 0,0001 & 0,0002 & 0,0032 & 0,0017 & 0,0002 & 0,0006 & 0,0004 & 0,0002 & 99,99 \\
\hline Fusão Alcalina & 0,0010 & 0,0004 & 0,0065 & 0,0080 & 0,0030 & 0,0025 & 0,0005 & 0,0002 & 99,74 \\
\hline Pirometalúrgico & 0,8000 & 0,0400 & 0,0250 & 0,0200 & 0,0300 & 0,0060 & 0,0003 & 0,0030 & 98,00 \\
\hline
\end{tabular}

Em relação ao impacto sobre o meio ambiente; a formação de gases é grande no processo convencional (pirometalúrgico), muito pequena no processo de fusão alcalina. Enquanto no processo pirometalúrgico se necessita de filtros e lavadores de gases, no processo eletrohidrometalúrgico isto não é necessário. As porcentagens de resíduos sólidos tomando-se por base a produção de chumbo são apresentadas na Tabela 2. As composições químicas médias aproximadas desses resíduos são mostradas na Tabela 3. 
Tabela 2: Porcentagem de resíduos sólidos nos processos.

\begin{tabular}{|l|c|}
\hline \multicolumn{1}{|c|}{ Processo } & Porcentagem de resíduos \\
\hline Eletrohidrometalúrgico & $6,0 \%$ \\
\hline Fusão Alcalina & $10,0 \%$ \\
\hline Pirometalúrgico & $25,0 \%$ \\
\hline
\end{tabular}

Tabela 3: Composição química porcentual dos resíduos sólidos em base seca.

\begin{tabular}{|l|c|c|c|c|c|c|c|c|c|c|}
\hline \multicolumn{1}{|c|}{ Processo } & $\mathbf{S b}$ & $\mathbf{S i O}_{2}$ & $\mathbf{A s}$ & $\mathbf{B i}$ & $\mathbf{C u}$ & $\mathbf{S n}$ & $\mathbf{F e}$ & $\mathbf{S}$ & $\mathbf{A g}$ & $\mathbf{P b}$ \\
\hline Eletrohidrometalúrgico & 60 & - & 2,2 & 0,100 & 3,00 & 3,0 & - & 10 & 0,5 & 20 \\
\hline Fusão Alcalina & 40 & 4,0 & - & - & 0,40 & 1,2 & 10 & 12 & - & 2,0 \\
\hline Pirometalúrgico & 0,05 & 20 & - & 0,001 & 0,75 & 0,10 & 30 & 1,0 & - & 1,5 \\
\hline
\end{tabular}

Uma importante fonte de informação, a Lead Development Association [9] , apresenta a produção de chumbo em minérios e acrescenta que $55 \%$ do chumbo consumido no mundo são procedentes de sistemas de reciclagem. Esta confirmação da importância da reciclagem de chumbo pode ser verificada na Figura 6.

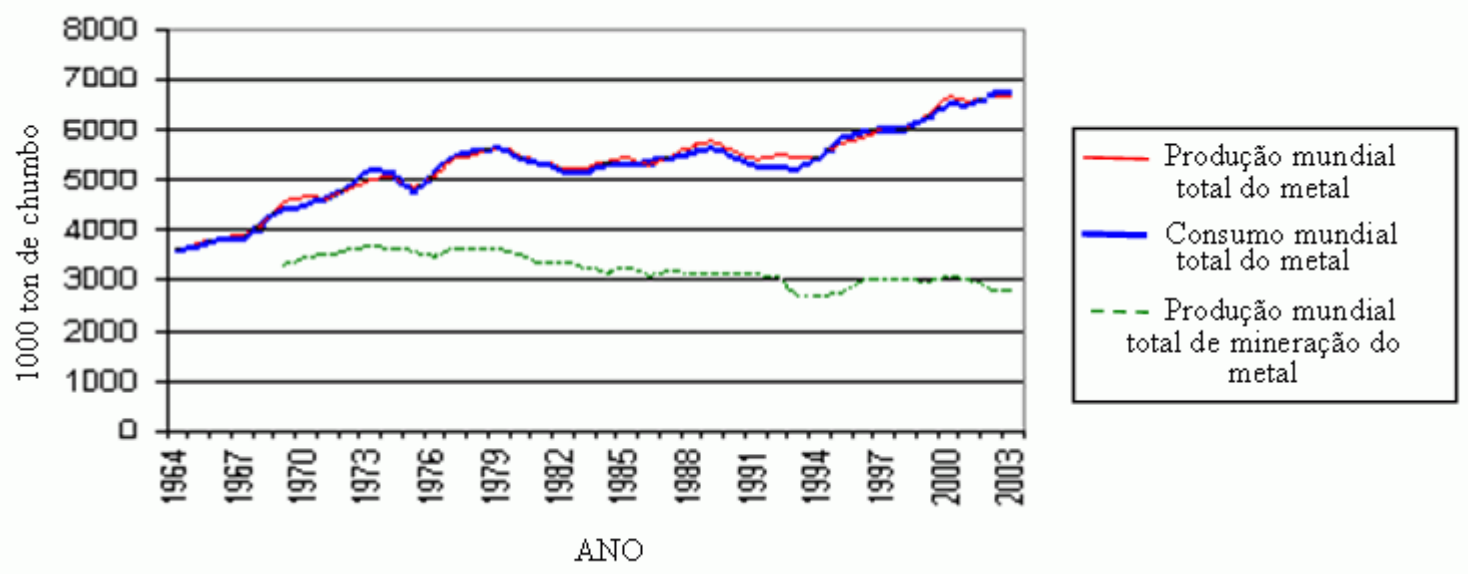

Figura 6: Produção mundial de chumbo.

$\mathrm{O}$ avanço da reciclagem, o esgotamento das fontes minerais além da consideração crescente dos conceitos de minérios urbanos (equivalente à coleta seletiva de metais) aponta um conjunto de mudanças tecnológicas que inevitavelmente deverão ocorrer. As mudanças mais previsíveis são as dos processos de empresas mineradoras que estão aumentando os seus custos para conseguir se enquadrar nas necessidades de preservação ambiental.

Tanto o sistema de fusão alcalina de chumbo como o processo eletrohidrometalúrgico para produção deste metal devem ser aperfeiçoados, para se tentar desenvolver processos alternativos, baseados nos mesmos princípios, para a produção de outros metais. Para tanto há que se trabalhar as plantas de laboratório por períodos longos, o que permitirá a obtenção dos parâmetros necessários para o desenho e construção de plantas pilotos. Estas plantas pilotos de tamanho suficiente fornecerão subsídios para a determinação das variáveis necessárias à elaboração de projetos de plantas industriais.

De grande importância é a reversão de sais de sódio para soda cáustica e enxofre, pois viabiliza economicamente o processo de fusão alcalina. Esse processo de reversão pode ser adaptado para se tentar resolver outros problemas ecológicos como o do balanço do enxofre na produção mundial de cobre, além da recuperação de sais de sódio que hoje se perdem em efluentes líquidos industriais. Assim, há que se acelerar os trabalhos de pesquisa e providenciar as patentes dos processos ao final do estudo. 
Há diminuição de oferta de chumbo no mercado interno, tanto em termos de minério de chumbo, quanto em termos de sucata de baterias exauridas, visto que devido às exportações, as baterias são enviadas para o exterior e o chumbo na forma de sucata tem seu retorno vetado por convenção internacional do ambiente (Basiléia).

Assim, devido à diminuição dos minérios de chumbo e também à diminuição da quantidade de matéria prima disponível para reciclagem de baterias automotivas, em função das exportações; conclui-se que há a necessidade de se associar grupos de pesquisa com empresas de processamento de minérios, tanto para parcerias em desenvolvimentos como para se utilizar os valiosos resíduos desta atividade econômica.

\section{REFERÊNCIAS BIBLIOGRÁFICAS}

[1] CHACÓN-SANHUEZA, A.E., FONTANETTI, A.R., BOCCHI, N., "Sistemas Innovadores de Producción de Plomo" In: INTERNATIONAL CONFERENCE ON CLEAN TECHNOLOGIES FOR THE MINING INDUSSTRY, VI CTMI, 2004, Concepción, Chile. Anais em CD 2004.

[2] FERRACIN, L.C., "Desenvolvimento de Processo de Produção de Chumbo Eletrolítico a Partir de Sucata de Baterias Automotivas", Projeto RHAE / CNPq, Processo Institucional No. 610044/98-2, 2001.

[3] OLPER M., MACCAGNI, M., COSSALI, S., "US Patent 5879830: Process for Regenerating Sodium Sulphide from the Sodium Sulphate Which Forms in Treating Lead Paste From Exhausted Batteries", 1999.

[4] MANEQUINI A.C., "US Patent 5630931: Process for the Hydrometallurgical and Electrochemical Treatment of the Active Mass of Exhausted Lead Batteries, to Obtain Electrolytic Lead and Elemental Sulphur", 1997.

[5] ZOPPI G., DI SOVICO, D., "US Patent 5391267: Process for the Production of Alkali Metal Hydroxides and Elemental Sulfur From Sulfur-Containing Alkali-Metal Salts”, 1995.

[6] GLOBAL ELETROQUíMICA INDÚSTRIA E COMÉRCIO DE METAIS LTDA, Banco de Dados Internos.

[7] FERRACIN L.C., CHACÓN-SANHUEZA, A.E., DAVÓGLIO, R.A., ROCHA, L.O., CAFFEU, D.J., FONTANETTI, A.R., ROCHA-FILHO, R.C., BIAGGIO, S.R., BOCCHI, N., "Lead Recovery From A Typical Brazilian Sludge Of Exhausted Lead-Acid Batteries Using An Electrometallurgical Process", Hydrometallurgy, v. 65, pp. 137-144, 2002.

[8] FERRACIN, L.C., CHACÓN-SANHUEZA, A.E., ROCHA, L.O., DAVÓGLIO, R.A., CAFFEU, D.J., FONTANETTI, A.R., ROCHA-FILHO, R.C., BIAGGIO, S.R., BOCCHI, "Evaluation Of Different Leaching Solutions For Lead Recovery From Lead-Acid Batteries". In: Southern Hemisphere Meeting on Minerals Technology and Brazilian Meeting on Minerals Processing and Extractive Metallurgy, VI SHMMT/XVIII ENTMME, 2001, Rio de Janeiro-RJ, Anais do congresso, v. 2, pp. 685-689, 2001.

[9] Lead Development Association, www.ldaint.org. Acessado em 23/02/2005. 